\title{
Ambito de la literatura americana
}

A moderna literatura americana, particularmente en el sur continental, acredita valores positivos de promesa, por los motivos artísticos que recoge y la riqueza de matices que la caracteriza. Desde el punto de vista estético, ofrece una labor de continuidad, con sentimientos universales, representando una época y un ambiente definidos, por el empuje y los rasgos de sus personajes, tan recios e íntimos. El llanto de la tierra y el rumor agreste de la selva, con sus misterios y tragedias, invade los poblados y llega a las ciudades. La anchura inconmensurable de las pampas, el galopar de los caballos, la reja del arado abriendo surcos perfumados en la tierra humilde y la fortaleza de las estribaciones cordilleranas que le sirven de marco, constituyen el paisaje vigoroso y centelleante, animado por una raza de hombres identificados en un ideal común literariamente concebido, que se abren paso a machetazo limpio entre la maraña de un mundo de complicaciones.

Los crudos soles del trópico, que en la tupida vegetación revienta en frutos de dulce frugalidad, hacen traspirar los hombres y la atmósfera y mueven a su conjuro una fauna y flora exóticas libradas al azar de los caprichos de la naturaleza tan pródiga en creaciones de soberbia plasticidad, con los innumerables meandros de sus ríos que riegan la tierra sedienta en donde la semilla fructifica presurosa y deposita el oloroso perfume agridulce de sus hojas, luego transformadas en humus fecundo y el quejido lastimero del indio que desde la montaña que convierte en habitación canta sus alegrías y angustias en quejumbrosa melodía que viene del tiempo y espera el instante de tomar contacto con la vida pública, tal el escenario en que actúan los personajes, animados por el viento de 
la sierra que en sus alas lleva las preocupaciones de un exuberante lirismo que envuelve el alma americana.

El dolor indio y la angustia mestiza, que en la figura de la mozá indigena y en los ojos tristes de la chola tienen la dulcedumbre del color y la luz refulgente en su vistosa indumentaria, y los pechos nervudos de sus hombres curtidos por los soles y las nieves eternas hacen creer en la resurrección de cíclopes en miniatura tallados en la dura roca, pero que se mueven, luchan, gimen y cantan como los antiguos pelasgos cuando tenían la misión de poblar el suelo y multiplicar por sus acciones el suelo desierto, removerlo, hacerlo fértil, cubrirlo en su extensión libre de monumentos enchapados en oro, convertir en arte la alfarería, dejándose mecer en la multitud de colores con que adornaban sus utensilios domésticos, jugar en poesía con las estrellas y hacerle el amor a las mujeres.

En sus diversas facetas la literatura americana tiene aquí su ámbito ilimitado de roca y melodía, de viento y mar anchos al abrazo, de tradición y arado, de selva y sentimiento que aparecen sin intermitencia en la obra de José de Alençar y Euclydes da Cunha, de Rómulo Gallegos y Mariano Azuela, de Ricardo Güiraldes y Lucio V. Mansilla, Manoel de Macedo, igual que Luizio de Acevedo, César Uribe Piedrahita como Ferreira de Castro, desenvuelven sus relatos del misterio infinito en la floresta, constituyendo una revelación para el mundo exterior que Horacio Quiroga llevó a la ciudad con su perfume de cielo y de leyenda.

Prodigios de arquitectura literaria y filológica son la obra de Andrés Rello y Rufino José Cuervo, artífices de la lengua, a la que arrancaron armonías nuevas como Rubén Darío y José Santos Chocano, con la emoción de Castro Alves, con sinfonía de himno, sobriedad de templo griego y fortaleza de honrado pecho, que en José Martí y José Enrique Rodó cobró armonías inusitadas. La literatura continental no es un producto de la fatalidad, a cuyas fuerzas tendrá que someterse, sino el resultado de una pasión incontenible que emerge de lo imponente del paisaje abrupto y de la llanura, desierta en secano y calcinada por lava de volcanes, y exuberante y voluptuosa en el desbordamiento de los grandes ríos caudalosos.

La vida encarna aquí todo el problema del individuo al que se asocian como contraste los agentes naturales. Vivir, para llenar la 
gran función creadora, exaltando a la plenitud los elementos que sirven al hombre para su existencia, envuelto en lujuria tropical, transformándolos de acuerdo con las propias necesidades estéticas. El hombre es el rey de la creación, y de los medios que la circundan se sirve en todos los grados de la escala social. Es por ello que a veces truena con furor impetuoso y otras se convierte en acogedora bonanza, ya con acentos cívicos y arranques elocuentes de expresión épica. Caprichosos en ritmo y métrica, desconcertantes y arrobadores, escritores y poetas marchan unidos en la acción del tiempo, sin obedecer a reglas prefijadas.

Tumulto de pasiones puede caracterizar a la literatura americana. En sus órdenes más diversos, hace derroche de emotividad, dentro de cuyo marco se encuentra bien. El proceso panorámico escapa al simbolismo, o en él se concentra, según el ambiente que respire. Sin haber alcanzado el abolengo histórico de los países europeos, ha trazado ya una ruta de porvenir en el que busca la creación fecunda que desembocará en una refinada civilización, como lo testimonian Augusto Arias desde su rincón de cielo, José Lins do Rego y Jorge Amado a través del paisaje de sus mangues, dentro de una naturaleza lujuriante y avasalladora que revienta pletórica de sudor y hechicería en las facendas, traspasando la tierra y el mar con una canción nueva. Esa misma nota encuéntrase en Demetrio Aguilera Malta deambulante por suburbios y esteros salados en exploraciones costeras, con sus balandras balanceándose dulcemente sobre las aguas dormidas, con su chola obsesionada de sensualismo arrebatador, y en José Américo de Almeida, buscando la verdad en el interrogante de la adivinación, distrayéndose mientras espera, perdido en el laberinto de las cosas muertas.

Misteriosa como la selva misma es la obra de Gil Gilbert, que respira el lamento y los alaridos dentro de la noche en la que el hombre habita y se entierra, ojos y oídos abiertos a las emociones que vienen del fondo del mundo, con sus lenguas de fuego, rozando el rostro que yace aplastado por el cansancio y dormido en brazos del miedo y la desesperación, y en el suelo se convierte en raíces todo él, para repetir luego, a través de las generaciones, mucho tiempo después, atravesando distancias, las palabras de Bernardo Arias Trujillo, al trote por los valles altos de las nubes, amansando vientos bravos a falta de potrancas briosas. Al otro extremo en- 
contramos a Julián Padrón, con sus manos callosas, todo el cuerpo traspirando, cubierto de polvo hasta las cejas, embutido en el vaho que viene de la tierra reseca, con sus rodar de carretas que arrastran caballos cansados en la tarde calcinada.

A la inversa, en Gallegos Lara los que se van, envueltos en el drama de las necesidades de la vida tortuosa, perdidos, braceando en las estancadas aguas del olvido, con su dolor humilde de buhardillas en azotea's desmanteladas por ráfagas de tormentas, soles y vientos que vienen de los cuatro puntos cardinales y ahogan la canción dolorida del indio. Semejanza de ese proceso, en calor y trabajo rudo, crudeza y lágrimas arrancadas del sufrimiento, trasciende de la obra de Jorge de Lima, en prosa y verso y en Affonso Schmidt, con sus relatos plásticos de la brutalidad desconcertante por lo despiadada, igual que en Alfredo Varela con su río oscuro que acoge en su seno materno los cuerpos inertes procedentes de las selvas chaqueñas y suavemente los va ofreciendo al mar como obsequio de nuestro tiempo de escupir. Jorge de Lima ha simbolizado las dimensiones de esta tragedia en estrofas de honda amargura, en dulcedumbre de caridad y conmiseración cristianas, tomando como tema de inspiración los negros que los toboganes sepultan en el fondo de las bodegas de los barcos carboneros, a quienes recuerda en oración de místico arrobamiento, enterneciendo el alma con el encantador hechizo de Guilherme de Almeida.

Alfredo Pareja y Díez Canseco, ahogado por las mismas aguas que invaden los límites, arrasan los muelles y corren pausadas por los esteros, y José Geraldo Vieira en el otro extremo del panorama, han rociado de angustiosa eternidad ese mundo cruel de realidades inconcebibles del que emergen gritos desgarradores que parten el alma. Benjamín Carrión, con José Carlos Mariátegui y Luis Alberto Sánchez han animado toda una generación de escritores y poetas, lanzada a través del territorio humano de América a la búsqueda de un sentimiento que exprese el derrotero de una literatura que llegue al fondo del alma. Y como en el caso de Curvelho de Mendoza y Fabio Luz exponga plásticamente cuanto de recóndito brota del corazón en todas las latitudes emotivas que Jorge Carrera Andrade tradujo, con sus paisajes manufacturados y horizontes vendidos, en poemas de hondo sentimiento detenido en el verso pulcro de Guillermo Valencia, que a veces, como inesperado fantasma, sonám- 
bulo y quimérico reaparece en José Asunción Silva, con sus paraísos sinuosos y complicados e infiernos acogedores con tibieza de hogareño rescoldo.

En la entraña misma de América ha urdido Germán Arciniegas, cual ningún otro escritor contemporáneo después de Antonio Caso y Baldomero Sanín Cano, una obra fecunda, rica de matices y múltiple en contenido espiritual. Lo acredita como una de las figuras más prominentes de esta generación, que Waldo Frank espoleó en prosa de largo alcance continental y Joaquín García Monge toma por doctrina de contenido que abarca el universo de América. Desde el mismo ángulo habrá de juzgarse la labor de Mariano Picón Salas en su ámbito, por cuanto tiene de expresión universalista en el panorama continental. Nervio macizo en sus estudios literarios, ha indagado en la conciencia americana, igual que Arciniegas, poniendo en la obra tal pasión que le sitúa entre las conciencias liminares de su generación.

Determinado el arte continental a imponerse por las características de su propia expresión y sentimiento, en su corta historia no ha escatimado energías ni vigor emotivo para colocarse en el camino de su porvenir. Viviendo en poesía permanente, el arte americano se identifica con el ambiente y percibe el rumor de la calle y de la selva, ya sea plásticamente, en poesía como en prosa. Fernán Silva Valdés, Ismael Enrique Arciniegas, Alvaro Moreyra y Ribeiro Couto llenan las páginas de la historia literaria con producciones de poética belleza, a través de la cual habla todo un pueblo determinado a seguir adelante. E1 mismo testimonio presentan Graciliano Ramos y Benito Lynch, Enrique Serpa y Erskin Caldwell, como portavoces de una fuerza humana, opulenta de eternidad.

Recorrer el panorama artístico del hemisferio no resulta empresa fácil, por el número de testimonios vivientes que reunir, y difícil su clasificación dentro de un mar de caprichos tan nutrido que trastornan el equilibrio intelectual. En lo que va de nuestro siglo es tan rica la producción artística de esta parte del mundo y tan acentuados sus valores que por ello se ubica entre los aportes más significativos que en su juventud pueblo alguno haya incorporado al acervo universal.

Campio Carpio. 
